\title{
El Chile intramuros de las narrativas de encierro
}

\author{
Ramiro Esteban Zó ${ }^{1}$ \\ Centro Interdisciplinario de Literatura Hispanoamericana, \\ Facultad de Filosofía y Letras, Mendoza, Universidad Nacional de Cuyo, Argentina
}

Resumen: La génesis escritural de ciertos relatos testimoniales latinoamericanos está condicionada por la violencia carcelaria del encierro de los propios autores, a menudo militantes e intelectuales comprometidos con causas liberacionistas en tiempo dictatoriales. Esta escritura se concibe desde, sobre y en torno a la cárcel y esta condición de encierro permea considerablemente la génesis de estos textos. En esta génesis escritural la visión de la cárcel, del lugar de reclusión, del espacio subjetivo del testigo-víctima-autor cobra un significado imprescindible a la hora de leer estos textos: ¿cómo se percibe y se siente el espacio intramuros? ¿Cómo se lo caracteriza? ¿Cómo verbalizan este espacio del terror estos autores? ¿Cómo se puede hablar de este "hogar de los cautivos" (Quijada Cerda, 1977)? ¿Hay conexión entre la Chile intramuros y la extramuros dentro de la reclusión? En este estudio se intentará analizar la visión de la "Chile intramuros" de las siguientes narrativas de encierro: Tejas verdes. Diario de un campo de concentración en Chile de Hernán Valdés (1974), Cerco de púas. Un candente testimonio de represión de Aníbal Quijada Cerda (1977), Dawson Isla 10 de Sergio Bitar (1987) y Frazadas del estadio de Jorge Montealegre I (2003).

Palabras clave: Chile intramuros; Narrativas de encierro; Discurso testimonial latinoamericano; Dictadura latinoamericana.

Título: O Chile intramuros das narrativas de confinamento

Resumo: A gênese escritural de certos relatos de testemunho latino-americanos está condicionada pela violência carcerária do confinamento dos próprios autores, muitas vezes militantes e intelectuais comprometidos com causas libertárias em tempos ditatoriais. Esta escrita é concebida a partir, sobre e em torno ao cárcere e essa condição de confinamento permeia consideravelmente a gênese desses textos. Nessa gênese escritural, a visão do cárcere, do local de reclusão, do espaço subjetivo da testemunha-vítima-autor, assume um significado essencial no momento da leitura desses textos: como se percebe e se sente o espaço intramuros? Como é caracterizado? Como verbalizam esse espaço de terror esses autores? Como se pode falar desta "casa dos cativos" (Quijada Cerda, 1977)? Existe uma conexão entre o Chile intramuros e o extramuros dentro do confinamento? Neste estudo buscaremos analisar a visão do "Chile intramuros" das seguintes narrativas de confinamento: Tejas verdes. Diario de un campo de concentración en Chile de Hernán Valdés (1974), Cerco de púas. Un candente testimonio de represión de Aníbal Quijada Cerda (1977), Dawson Isla 10 de Sergio Bitar (1987) e Frazadas del estadio de Jorge Montealegre I (2003).

\footnotetext{
${ }^{1}$ Doctor en Letras por la Universidad Nacional de Cuyo-UNCuyo, Mendoza, Argentina. Posdoctorado en Historia por la Universidade Federal do Rio Grande do Sul-UFRGS. Profesor en la Facultad de Filosofía y Letras de la Universidad Nacional de Cuyo, Mendoza, Argentina. Orcid: http://orcid.org/0000-0002-3601-3597

E-mail: ramirozo2002@yahoo.com.ar
} 
Palavras-chave: Chile intramuros, narrativas de confinamento, discurso testemunhal latinoamericano, ditadura latino-americana.

Title: The intramural of Chile in the narratives of confinement

Abstract: The scriptural genesis of certain Latin American testimonial accounts is conditioned by the prison violence of the confinement of the authors themselves, often militants and intellectuals committed to liberationist causes in dictatorial times. This writing is conceived from, on and around the prison and this condition of confinement permeates considerably the genesis of these texts. In this scriptural genesis, the vision of the prison, of the place of seclusion, of the subjective space of the witness-victim-author takes on an essential meaning when reading these texts: how is the intramural space perceived and felt? How is it characterized? How do these authors verbalize this space of terror? How can you talk about this "home of the captives" (Quijada Cerda, 1977)? Is there a connection between Chile within the walls and outside the walls within the seclusion? In this study we will try to analyze the vision of "Chile intramuros" of the following confinement narratives: Tejas verdes. Diario de un campo de concentración en Chile of Hernán Valdés (1974), Cerco de púas. Un candente testimonio de represión of Aníbal Quijada Cerda (1977), Dawson Isla 10 of Sergio Bitar (1987) and Frazadas del estadio of Jorge Montealegre I (2003).

Keywords: Intramural Chile; Confinement narratives; Latin American testimonial discourse; Latin American dictatorship.

\section{Introducción}

La génesis escritural de ciertos relatos testimoniales latinoamericanos está condicionada por la violencia carcelaria del encierro de los propios autores, a menudo militantes e intelectuales comprometidos con causas liberacionistas en tiempo dictatoriales. Esta escritura se concibe desde, sobre y en torno a la cárcel y esta condición de encierro permea considerablemente la génesis de estos textos. En esta génesis escritural la visión de la cárcel, del lugar de reclusión, del espacio subjetivo del testigo-víctima-autor cobra un significado imprescindible a la hora de leer estos textos: ¿cómo se percibe y se siente el espacio intramuros? ¿Cómo se lo caracteriza? ¿Cómo verbalizan este espacio del terror estos autores? ¿Cómo se puede hablar de este "hogar de los cautivos" (QUIJADA CERDA, 1977)? ¿Hay conexión entre la Chile intramuros y la extramuros dentro de la reclusión? En este estudio se intentará analizar la visión de la "Chile intramuros" de las siguientes narrativas de encierro: Tejas verdes. Diario de un campo de concentración en Chile de Hernán Valdés (1974), Cerco de púas. Un candente testimonio de represión de Aníbal Quijada Cerda (1977), Dawson Isla 10 de Sergio Bitar (1987) y Frazadas del estadio de Jorge Montealegre Iturra (2003). 


\section{Características de este discurso testimonial}

El testimonio trata de registrar lo vivido; por ende, es esencial la relación de la palabra con lo que está "más allá", con el referente, con lo que se recuerda e intenta transformarse en discurso pero que a la vez se resiste, porque lo siniestro no encuentra cómo plasmarse en la escritura. Como en la narrativa testimonial el autor participa de lo narrado, se abren interrogantes acerca de la verdad histórica y el papel del punto de vista en el acto de escritura: no hay lectura del pasado que no interprete. Tal paradoja del realismo nos hará buscar en cada testimonio los supuestos o las premisas del texto que generan ciertos silencios.

La pluralidad genérica del testimonio da cuenta de un intento de la víctima-testigorelator-confeso-creador y en ocasiones investigador de apropiarse de los recuerdos de un pasado cruento y duro para su existencia o de dar cuenta de su martirio actual en forma de diarios de cárcel. El discurso testimonial siempre es personal y subjetivo aunque en ocasiones intenta describir o manifestar una experiencia o situación colectiva, el yo confesovíctima-testigo se torna en nosotros acusador-militante-reflexivo. Pero el subjetivismo de la escritura nunca se pierde aunque se articule o cristalice en un yo o en un nosotros, siempre la sensibilidad intentará manifestarse textualmente.

La literatura testimonial es sobre todo la que da cuenta sobre los vejámenes, el encierro y la tortura es una narrativa personal pero colectiva a la vez. Así mismo es una escritura solidaria e incluso terapéutica, se escribe para soportar el dolor, para sobrevivir al encierro y a la tortura, para curar heridas. Muchas veces es utópica, permanentemente la víctima-testigo-autor piensa, desea y se obsesiona en la libertad: se imagina fuera de los muros, realiza planes para el momento de salir e incluso se construye una vida paralela a la carcelaria: dos individuos: el cautivo y el hombre libre.

\section{La conexión entre el Chile intramuros y el extramuros en Tejas verdes.}

\section{Diario de un campo de concentración en Chile}

El autor testimonial debe luchar permanentemente entre lo que puede decir y lo que debe callar, puesto que siempre "la narración de la experiencia está unida al cuerpo y a la voz, a una presencia real del sujeto en la escena del pasado" (SARLO, 2005, p. 29). Y es que si bien la experiencia es fundamental en el testimonio, también lo es la narración, ya que "el lenguaje libera lo mudo de la experiencia, la redime de su inmediatez o de su olvido y la convierte en lo comunicable, es decir, lo común" (SARLO, 2005, p. 29, en cursiva en el original).

Los autores que hemos analizado pertenecen a la cultura letrada, muchos de ellos además de ser militantes, activistas políticos o miembros de un gobierno democrático formaban parte de la cultura letrada de los países que habitaron durante los golpes cívico- 
militares. Puesto que muchos de ellos eran profesores, escritores, maestros, periodistas, entre muchas profesiones afines a la cultura letrada. De esta forma, aún más la tensión entre lo que se puede decir y lo que debe callarse se intensifica, porque estos miembros de esta red representaron la voz testimonial de aquellos secuestrados $y / o$ torturados que por no pertenecer a la cultura letrada no podían llegar a verbalizar las experiencias de cautiverio.

Todos los textos que hemos estado analizando hablan, cuentan, relatan y testimonian sobre el encierro, no son experiencias enmudecidas como pueden haber existido dentro de los diversos espacios de cautiverio durante las dictaduras latinoamericanas. Estas narrativas personales de algún modo se oponen a la idea de "lo intestimoniable", la figura del "musulmán" (der Muserlmann) de Agamben (2000, p. 41) 44. Este "musulmán" (puede aplicarse desde los campos de concentración nazis como los latinoamericanos o las cárceles en nuestro continente durante las dictaduras) es aquel que "ha tocado fondo" y se ha convertido en un verdadero "no-hombre" por la tortura y la violencia del encierro. Lo que lo lleva a este musulmán a considerar como una tarea difícil "testimoniar", para eso pueden estar otros. Otros individuos como estos autores analizados que gracias a su cultura letrada han podido salvarse de "tocar fondo" y de volverse "no-hombres" a pesar de la violencia carcelaria, para poder testimoniar sobre las propias experiencias y la de tantos "musulmanes" o "intestimoniables" latinoamericanos que tuvieron un silencio forzoso en prisión.

La primera narrativa del encierro que hemos elegido para descifrar la visión del espacio chileno intramuros y extramuros es Tejas verdes. Diario de un campo de concentración en Chile (1974) de Hernán Valdés.

En 1974, Valdés publica en su exilio en Barcelona este discurso testimonal de sus dos meses de encierro y torturas en el campo de concentración de ese nombre. Ya desde su prólogo Valdés reconoce la "profunda repugnancia" que la génesis escritural del texto le ha provocado a la hora de constituirse como porta voz de la experiencia del pueblo chileno. En el libro, Valdés reconstruye -es un diario reconstruido, ya que no pudo escribir estando privado de libertad- su detención (entre el 12 de febrero y el 15 de marzo de 1974) y paso por el Campo de Concentración de Tejas Verdes, el Campamento № 2 de Prisioneros de la Escuela de Ingenieros Militares "Tejas Verdes".

En un episodio de Tejas verdes, podemos vislumbrar lo que Mabel Moraña (1988) ha dado en llamar el sobredimensionamiento del texto a partir de la censura. Cualquier texto que no responda a los patrones impuestos "es sospechoso y peligroso a priori en cuanto evade el régimen de disciplinamiento social, siendo por tanto considerado al menos como disfuncional con respecto al sistema" (MORAÑA, 1988, p. 134). La sobrevaloración de la palabra escrita o verbalizada en una canción o en otras formas expresivas asume proporciones grotescas. "El texto es perseguido y secuestrado, requisado y destruido, exactamente igual que los individuos de la sociedad que lo produce" (MORAÑA, 1988, p. 134). En Tejas verdes se narra cómo los guardias infieren conclusiones absurdas sobre supuestos mensajes cifrados en cuadernos de una víctima: "-Y este libro en clave. ¿Te estai 
haciendo el tonto? Ya, llévatelo a cantar arriba. -El libro es de Eva -grito, jadeando-. Está escrito en su idioma. -Vai a descifrarlo al tiro, o huevón, o te capamos" (24)².

Ante la persecución del texto y de sus productores y consumidores, el discurso popular responde escribiendo, para desafiar al discurso dominante, que opera como "referencia de oposición", es decir, "como el negativo o la imagen invertida de una realidad que debe ser revelada" (MORAÑA, 1988, p. 134). Para ello se recurre a una forma mixta, que puede acusar y desenmascarar al oponente, erigiéndose, al mismo tiempo, en proyecto de restauración simbólica de una época.

En Tejas verdes, en el apartado correspondiente al jueves 14 de febrero Valdés nos da cuenta de la conexión entre el Chile intramuros y el Chile extramuros. El prisionero compara, coteja y contrapone su visión patética, miserable y tortuosa fruto de su experiencia carcelaria con la visión idílica de la "normalidad veraniega del lugar, de la conducta festiva de los propietarios que venían con sus familias a pasar el fin de semana, en tanto que el país es una carnicería" (VALDÉS, 1978, p. 61). Valdés posee una impresión de deja vu, de lo "ya visto y vivenciado", los espacios se repiten pero el pathos es diferente. La sensibilidad valdiana se evidencia en estos contrastes entre el afuera y el adentro, lo pasado y lo presente, lo recordado y lo sentido en la actualidad.

Valdés (1978) describe con lujo de detalles los contrastes entre el pasado y el presente:

\begin{abstract}
En efecto, por la entrada anterior de la empalizada donde hay dos torrecillas con ametralladoras, viene un grupo semejante al nuestro, trotando. La mayoría son muchachos. Pasan sin mirarnos casi y no alcanzo a distinguir bien sus rostros. Entran a algunas de las cabañas mientras nosotros salimos al exterior, Pasamos ante algunas tiendas llenas de militares y luego entramos a otro patio de empalizadas, donde hay más cabañas, una especie de cocina, mesas de grandes tablones. El baño está un poco más allá, en la falda del cerro.

-iTienen tres minutos pa', la corta y la larga y pa' lavarse!

El acceso al cerro está cortado por alambradas de púas. [...] Los asientos están hechos de cajones con una abertura ovoide, chorreados de mierda y mojados de orines. El olor es venenoso. La mierda forma abajo un grueso pantano burbujeante. Cubriéndome las narices con una mano, orino ayudándome con la otra. Y desde esta altura, capto buena parte del paisaje. Tengo de inmediato una impresión de $<$ ya visto>, pero no tanto por la similitud con Eva algunas horas, la última vez que salimos juntos a la costa, hace unas seis semanas. Ahí están las casas de buena parte de la burguesía chilena, bordeando el río Maipo. Y ésta es plena época de veraneo. Aquí, muy cerca, a cien o ciento cincuenta metros, el largo puente sobre el rio Maipo. Nos admirábamos, precisamente, de la normalidad veraniega del lugar, de la conducta festiva de los propietarios que venían con sus familias a pasar el fin de semana, en tanto que el país era una carnicería. Hay un par de soltados armados en su entrada, al frente nuestro. Esto es todo lo que alcanzo a ver en medio minuto. $Y$ las cuatro torres de las ametralladoras. Algunos se han sentado para cagar, pero deben cortar los intentos o el proceso ante la llamada del soldado (VALDÉS, 1978, p. 60-61).
\end{abstract}

\footnotetext{
2 Correspondiente al miércoles 13 de febrero. Cfr. Hernán Valdés. Tejas verdes. Diario de un campo de concentración en Chile. [1974] Barcelona: Editorial Laia, 1978.
} 
La dificultad de expresar o decir la fibra íntima tocada por el horror de la tortura no impide o prohíbe ni silencia a la víctima-testigo-autor sino que lo arroja a la necesidad de atestiguar lo sufrido. Las experiencias discursivas de Valdés, como las de Quijada Cerda o las de Bitar, ya no podemos considerarlas como narraciones objetivas, sino que son narrativas, ficciones o relatos personales claramente permeados por la memoria selectiva, no todo está narrado, relatado o ficcionalizado (JELIN, 2002).

La disquisición genológica entre lo testimonial y ficcional a menudo, los propios autores la complejizan, como es el caso del propio Valdés que considera a su texto Tejas verdes como un libro-denuncia testimonial y documental, pero reconoce que a menudo se lo ha leído como una novela y termina reconociendo que es una ficción que llegó a ser best seller en los setenta:

[...] la función que yo le asignara al libro se cumplía con éxito: a través de cientos de testimonios yo podía saber que cada lector se había situado de inmediato en la experiencia de la víctima y que de alguna manera, en su mundo privado o en su vida pública, había reaccionado. Este libro debe haber sido $-y$ espero que siga siéndolo- un grano de arena en la formación de todo ese movimiento internacional de repulsa al régimen chileno.

$[\ldots]$

Este libro no pretende seguir presentándose hoy como una denuncia inmediata de los hechos relatados; pero sí pretende seguir siendo un instrumento de denuncia permanente de aquella obscena brutalidad [...]

$[\ldots]$

Muchos lectores, además de percibir esas posibles funciones, hacen una lectura distinta, cuyos alcances no dejan de sorprenderme: leen una "novela". Incluso compañeros que vivieron situaciones parecidas, que saben del carácter documental de cada detalle, dicen: "cuando en tu novela", "... ese personaje de tu novela...", etc., implicando así que la escritura, por su propia naturaleza, transformaría la experiencia más directa fatalmente en una especie de ficción. Como sea que se lo percibe literariamente, lo que cuenta es que este libro siga conservando su actualidad que trasciende, estoy seguro, sus referencias concretas (VALDÉS, 1978, p. 9-10).

Y es que si es que la víctima-testigo-autor considere o no, más cerca de lo ficcional su discurso, lo que no entra en discusión es que su relato es una "memoria viva" de lo sucedido que intenta reactualizar para concientizar a los lectores no solo de los vejámenes producidos sino también para que estos hechos no vuelvan a sucederse jamás.

Jorge Montealegre Iturra también se preocupa por aclarar la génesis escritural de su narrativa de encierro, aún más tras una distancia temporal de treinta años de su cautiverio. Nacido en 1954, comenzó a escribir en la prisión política a los diecinueve años. Publicó en Roma en 1974, su testimonio Chacabuco en una edición mimeografiada. Ese testimonio sería entregado a la III Sesión de la Comisión Investigadora de los Crímenes de la Junta Militar Chilena celebrada en México en febrero de 1975, y a la que he hecho referencia en capítulos anteriores. En Ortúzar (1977) hay otra tentativa testimonial de Montealegre.

Ya había incursionado en el testimonio de sus experiencias en otros campos de 
reclusión con su obra Chacabuco (1975) con una lógica de denuncia política. Pero en el 2003 publica Frazadas del Estadio Nacional, una narrativa intensa del encierro en el Estadio Nacional, lugar privilegiado de la memoria de la represión que en el 2002 fuera declarado monumento nacional. Este Chile intramuros verbalizado por Montealegre es retomado gracias a los "dictados de la memoria" a través de un proceso de desdoblamiento de la personalidad del autor en diversas personas "cobijadas por la frazada de la memoria": el joven lolo Montealegre de 19 años que tomaron preso en septiembre de 1973 y el viejo Montealegre, de cincuenta años que recuerda, reconstruye, revela y retorna el pasado. La frazada será cobijo, abrigo no solo del frío, sino también reparo metafórico del peligro del olvido.

En el relato de Montealegre no solo paredes, rejas, piso, etc., son elementos espaciales dentro del cautiverio, sino que la frazada llega a ser el "único lugar privado", el espacio de este Chile intramuros en el que el preso recuperaba cierta íntima libertad, el último bastión de refugio de un pasado infantil, es una plataforma espacial para catapultarse a sueños evasivos hacia el Chile extramuros. La frazada era el único lugar privado. Ella envolvía nuestros sueños y nuestros deseos. La frazada recordaba frazadas más cariñosas. En último caso, podíamos dormir empuñándola como un niño aferrado a su "tuto" para dormir sin miedo. En la mañana amanecíamos acurrucados bajo la manta "en otra parte". Y era mejor no abrir los ojos para seguir soñando (MONTEALEGRE, 2003, p. 59-60).

El experimentado Montealegre pretende volver a la oscuridad para que la imagen del horror se revele. Intenta hacerse cargo de la orfandad del joven Montealegre, protegerlo, ser su tutor e invitarlo a ser co-autor de este testimonio. Montealegre joven y Montealegre viejo, pasado y presente escriben a cuatro manos estos relatos del terror para redescubrirse a sí mismo. Viaje escritural hacia el pasado con un respeto extremo a lo vivido: "He respetado su relato. Me he resistido a novelar y a incorporar elementos de ficción. Tentaciones no me han faltado. Sin mayores pretensiones literarias, deseo que tenga el valor de un testimonio fidedigno. Un medio de pruebas. Con mis opinables puntos de vista. Lo de ayer y de hoy" (MONTEALEGRE, 2003, p. 15). Montealegre reconoce una lucha constante entre testimoniar y ficcionalizar, lo que le sucede a muchos de estos autores. Aquí se produce lo que Elizabeth Jelin $\left(2002,2014^{39}\right)$ da en llamar la "temporalidad compleja" (JELIN, 2002) o "las múltiples temporalidades del testimonio" (JELIN, 2014). En esta "narrativa personal" como la llama Jelin, Montealegre evidencia la complejidad en materia temporal, puesto que los testimonios como el del chileno "ubica[n] directamente el sentido del pasado en un presente, y en una función de un futuro deseado" (JELIN, 2002, p.12). Estas narrativas personales que intentan dar cuenta de lo pasado también dependen claramente de lo empírico que modifica y transforma los recuerdos de estos hechos cruentos. El hecho de "ubicar temporalmente a la memoria significa hacer referencia al 'espacio de la experiencia' en el presente. El recuerdo del pasado está incorporado, pero de manera dinámica, ya que las experiencias incorporadas en un momento dado pueden modificarse en períodos posteriores" (JELIN, 2002, p. 13). 
La frazada era el único lugar privado. Ella envolvía nuestros sueños y nuestros deseos. La frazada recordaba frazadas más cariñosas. En último caso, podíamos dormir empuñándola como un niño aferrado a su "tuto" para dormir sin miedo. En la mañana amanecíamos acurrucados bajo la manta "en otra parte". Y era mejor no abrir los ojos para seguir soñando (MONTEALEGRE, 2003, p. 59-60).

La frazada es una suerte de leit motiv durante todo el relato, no solo le da el título al texto, sino a uno de los capítulos "Frazadas del sueño" y también Montealegre reconoce en ese elemento un factor de unión pero también de tensión entre los presos: "La frazada llegó a ser una verdadera moneda de cambio. Volviendo al trueque más primitivo, hubo quienes cambiaron calor por alimento. Así, una frazada se podía trocar por uno o dos panes" (MONTEALEGRE, 2003, p. 59).

Considerar a la frazada como "espacio libertario" de alguna forma nos hace pensar en la letrina de Jorge Semprún presente en su testimonio La escritura o la vida (1997). Ambos elementos: la frazada para Montealegre y la letrina para Semprún ofrecen al cautivo una escapatoria y una evasión al tormento de la reclusión. Para Semprún, las letrinas son "una especie de refugio donde encontrarse con compatriotas [...] un lugar donde intercambiar noticias, [...] recuerdos, risas, un poco de esperanza [...] era un espacio de libertad" (SEMPRÚM, 1997, p. 52). Lo escatológico de la letrina y lo rústico de la frazada no impiden que el prisionero emplee este espacio y este elemento como refugios ante la violencia del encierro.

\section{La inhibición del lenguaje y la verbalización del espacio chileno carcelario}

El espacio chileno carcelario, este Chile intramuros es un "recinto afásico" en el que el lenguaje pierde o adolece su significado, la palabra se empobrece, se contradice, se embrutece, se encapsula y se la violenta. Es la negación de la palabra, del conocimiento, del saber, de la comunicación y de la expresión. La semántica se modifica, muta, se hace imprevisible y se deshumaniza. La cárcel desde su nomenclatura cohíbe el lenguaje y además contradice la libertad de palabra, de cuerpo y de identidad. Los autores en estas narrativas de encierro nos presentan una cruel realidad: el encierro como silencio total del ser humano. La violencia carcelaria es casi invisible y silenciosa pero sumamente efectiva. La prisión silencia, enmudece y hasta congela al preso en un "enfriamiento" de la persona para lograr una "supuesta solución" al "problema de los presos políticos". El cautiverio destruye tanto mental como físicamente al individuo.

Muestras de esta inhibición del lenguaje en un escrito carcelario chileno la encontramos en Cerco de púas. Un candente testimonio de la represión (1977) de Aníbal Quijada Cerda, novela testimonial que obtuvo el Premio Casa de las Américas en ese año. Es el relato de su encarcelamiento en una prisión en la Isla de Dawson en Magallanes por su afiliación al partido comunista. 
En el segundo capítulo de Cerco de púas -luego de haber descrito la "bienvenida" que recibió Aníbal Quijada Cerda con un interrogatorio repleto de insultos y amenazas con armas de fuego por parte de los guardias y la "incomunicación previa" que representaban las carpas antes de pasar al encierro propiamente dicho detrás de la alambrada- el texto nos narra la dinámica carcelaria que inhibe claramente el lenguaje proscribiéndolo y convirtiéndolo en delito:

\footnotetext{
La prohibición de conservar era absoluta.

El que habla paga -advertía el sargento, para lo cual los custodios estaban muy atentos tras la alambrada. Desde el portón, dos de ellos apuntaban permanentemente con sus armas. Y no pasaba mucho tiempo sin que alguno de los presos fuera llamado por el delito de conversar.

El pago se realizaba en la explanada: varias horas a la intemperie o la práctica de duros ejercicios (QUIJADA CERDA, 1977, p. 11-12).
}

En la dinámica del cautiverio, estos narradores testimoniales reconocen la inhibición lingüística como un elemento axial del confinamiento, como lo sucede con el chileno Sergio Bitar en su novela Dawson. Isla 10, que reproduce otra reclusión en la isla chilena por ser ministro de Minería de Salvador Allende. Bitar igual que Quijada Cerda reconoce la prohibición y censura tanto de la capacidad de leer como de comunicarse por escrito de los presos:

Nuestras pertenencias habían sido registradas desde un principio y no teníamos prácticamente nada. Lo que les importaba, al parecer, era que no escribiéramos: había prohibición tajante. Los primeros días, incluso, no tuvimos papel de ninguna clase. Los libros que poseíamos ya habían sido revisados por la Inteligencia Naval, para asegurarse de que no contenían "material subversivo" (BITAR, 1987, p. 50).

\section{Conclusión}

En este trabajo se intentó examinar la descripción de la vida en prisión dentro de algunas narrativas de encierro chilenas: la perspectiva estructural de la prisión, la rutina del cautiverio, la inhibición lingüística, los intentos por comunicarse de los presos, la resistencia verbal del prisionero, como Hernán Valdés, Aníbal Quijada Cerda, Sergio Bitar y Jorge Montealegre Iturra.

Se debe reconocer que el testimonio trata de registrar lo vivido; por ende, es esencial la relación de la palabra con lo que está "más allá", con el referente, con lo que se recuerda e intenta transformarse en discurso pero que a la vez se resiste, porque lo siniestro no encuentra cómo plasmarse en la escritura. El discurso testimonial siempre es personal y subjetivo aunque en ocasiones intenta describir o manifestar una experiencia o situación colectiva, el yo confeso-víctima-testigo se torna en nosotros acusador-militante-reflexivo. Pero el subjetivismo de la escritura nunca se pierde aunque se articule o cristalice en un yo o 
en un nosotros, siempre la sensibilidad intentará manifestarse textualmente.

Este trabajo pretende profundizar en el análisis de una red testimonial iberoamericana configurada por ciertos intelectuales, escritores, periodistas y militantes que han sabido cristalizar a través de la escritura sus experiencias de cautiverio en el periodo dictatorial en el cono Sur.

\section{Referencias}

AGAMBEN, . Lo que queda de Auschwitz. El archivo y el testigo. Homo Sacer III. Valencia: Pretextos, 2000.

ALMEDA, E. Corregir y castigar. El ayer y hoy de las cárceles de Mujeres. Barcelona: Bellaterra, 2002.

ALMEDA, E. Mujeres encarceladas. Barcelona: Ariel, 2003.

ALZUGARAT, A. El discurso testimonial uruguayo del siglo XX. Montevideo: Biblioteca Nacional, 2009.

ALZUGARAT, A. Trincheras de papel. Dictadura y literatura carcelaria en Uruguay. Montevideo: Trilce, 2007.

AVELAR, I. Alegorías de la derrota: la ficción postdictatorial y el trabajo del duelo. Santiago: Editorial Cuarto Propio, 2000.

BACCI, C.; OBERTI, A. (coords.). Dossier: Testimonio: debates y desafíos desde América Latina. Clepsidra, vol. 1, n. 1, 2014. En línea: http://ppct.caicyt.gov.ar/index.php/clepsidra/issue/view/Clepsidra.\%20Revista\%20Interdisci plinaria\%20de\%20Estudios\%20sobre\%20Memoria.\%20Marzo\%202014.\%20A\%C3\%B10\%201 \%2C\%20N\%C3\%BAmero\%201/showToc. Consultado: 19/09/2014.

BITAR, S. Dawson. Isla 10. Santiago de Chile: Pehuén, 1987.

CARLEN, P. Sledgehammer: Women's Imprisonment at the Milenium. Londres: Macmillan Press LTD, 1998. https://doi.org/10.1057/9780230375352

CELS, MINISTERIO PÚBLICO DE LA DEFENSA DE LA NACIÓN, PROCURACIÓN PENITENCIARIA DE LA NACIÓN (comp.). Mujeres en prisión: los alcances del castigo. 1. ed. Buenos Aires: Siglo Veintiuno Editores, 2011.

DE ARMAS, G.; GARCÉ, A. Uruguay y su conciencia crítica. Intelectuales y política en el siglo XX. Uruguay: Trilce, 1997.

FERNÁNDEZ BENÍTEZ, H. M. The moment of testimonio is over: problemas teóricos y perspectivas de los estudios testimoniales. Íkala, revista de lenguaje y cultura, v. 15, n. 24, p. 47-71, enero-abril 2010.

FERRARO OSORIO, M. “Los manuscritos de El método y otros juguetes carcelarios”. En: Carlos Liscano. Manuscritos de la cárcel. Edición Fatiha Edmhand. Montevideo: Ediciones del caballo perdido, 2010. 43-58.

FOUCAULT, M. Vigilar y castigar: nacimiento de la prisión. 17. ed. Buenos Aires: Siglo 
Veintiuno, 1989.

GARAÑO, S. "Entre resistentes e 'irrecuperables': Memorias de ex presas y ex presos políticos". Tesis de licenciatura. Licenciatura en Ciencias Antropológicas. Orientación Sociocultural. Defendida el 25 de marzo 2008.

GARCÍA, G. V. La literatura testimonial latinoamericana. Madrid: Pliegos, 2003.

GINZBURG, C. El hilo y las huellas. Lo verdadero, lo falso, lo ficticio. Argentina, Fondo de Cultura Económica, 2010b.

GINZBURG, C. La prueba, la memoria y el olvido, Contrahistorias. La Otra Mirada De Clio, Segunda serie, n. 14, México, Marzo-Agosto: 2010a. p. 105-116.

GINZBURG, C. Sólo un testigo. En: Friedlander, S. (comp.). En torno a los límites de la representación: El nazismo y la solución final. Argentina, Universidad Nacional de Quilmes, 2007.

GONZALEZ, C.; SCAVINO, D. et VENTURA, A. La violence politique dans la culture du Rio de la Plata des années 1960 à nos jours. Bordeux: Ameriber, 2010.

JELIN, E. Las múltiples temporalidades del testimonio: el pasado vivido y sus legados presentes. Clepsidra. Revista Interdisciplinaria de Estudios sobre Memoria, n. 1, p. 140-163, marzo 2014.

JELIN, E. Los trabajos de la memoria. Madrid: Siglo XXI, 2002.

JOZAMI, E. 2922 días. Memorias de un preso de la dictadura. Buenos Aires: Sudamericana, 2014.

MALONE, C. S. G. The Testimonial World: Affect and Ethics in Latin American Literature and Film (1969-1991). Tesis doctoral en Literatura por la U. Santa Cruz, 2013. Consultado: 22/07/2014.

MONTEALEGRE ITURRA, J. Frazadas del estadio. Santiago de Chile: LOM ediciones, 2003.

NAVARRETE BARRIA, S. B. La ilusión anamnética en las ficciones narrativas recientes: sobre memorias, traumas y testigos, Acta literaria, n. 48, p. 49-64, enero-junio 2014. https://doi.org/10.4067/S0717-68482014000100004

NEUMAN, E.; IRURZUN, V. J. La sociedad carcelaria: aspectos penológicos y sociológicos. Buenos Aires: Depalma, 1990.

NICOLÁS, G. y BODELÓN, E. (comps.). Género y dominación. Barcelona: Anthropos, 2009.

PENNA, J. C. Este corpo, esta dor, esta fome: notas sobre o testemunho hispanoamericano. In: SELIGMANN-SILVA, M. (org.) História, memória, literatura. Campinas: Ed. Unicamp, 2003.

PINO, M. Hacia una configuración de los corpus de postgolpes en el cono sur. Universum, n. 15, p. 233-240, 2000.

PRADA OROPEZA, R. De lo testimonial al testimonio: notas sobre el deslinde del discurso testimonio. En: René Jara et al (eds.). Testimonio y literatura. Minneapolis: Institute for the Study of Ideologies, 1986. p. 7-21.

QUIJADA CERDA, A. Cerco de púas. Cuba: Casa de las Américas, 1977.

RICCIO, A. Lo testimonial y la novela-testimonio. El pacto testimonial. Anales de literatura hispanoamericana, n. 20, 1991. p. 249-262. 
ROMÁN, M. Bibliotecas en el tratamiento penitenciario, Información, cultura y sociedad, n. 16, 2007. p. 35-54.

SARLO, B. Tiempo pasado. Cultura de la memoria y giro subjetivo. Una discusión. Buenos Aires: Siglo XXI, 2005.

SEMPRÚN, J. La escritura o la vida. Traducción de Thomas Kauf. Barcelona: Tusquets, 1997.

STREJILEVICH, N. Literatura testimonial en Chile, Uruguay y Argentina. 1970-1990. A Thesis submitted in partial fullmiment of the requirement for the degree of doctor of philosophy in The Faculty of Graduate Studies. The University. September, 1991.

TAUZIN CASTELLANOS, I. (coord.). Prisons d'Amérique latine: du réel à la métaphore de l'enfermement. (Hommage de I'ERSAL à Yves Aguila) Bordeaux: Presses Universitaires de Bordeaux, coll. Maison des pays ibériques, 2009.

VALDÉS, H. Tejas verdes. Diario de un campo de concentración en Chile. [1974] Barcelona: Editorial Laia, 1978.

YÚDICE, G. Testimonio y concientización. Revista de crítica literaria latinoamericana. La voz del otro: testimonio, subalternidad y verdad narrativa, año XVIII, 36: 2. - semestre, p. 207227, 1992. https://doi.org/10.2307/4530631

Recebido em: 08/11/2019.

Aceito em: 17/02/2019. 